\title{
Application of Descending Method in Probing Reasons of the Fuse Misfire \\ Ye Yuan ${ }^{1, a}$, Haiyan Zhang ${ }^{1, ~ a}$, Yi Tao ${ }^{2, b}$, Yong $\mathrm{Ji}^{1, \mathrm{c}}$ \\ ${ }^{1}$ Mechatronics Co.Ltd of Liaoning Huaxing, Jinzhou, 121017, China \\ 2 Beijing Sepcial Vehicle Academy, Beijing 100072, China \\ aemail: yuanye485202@126.com, bemail:taotaoyiyi@163.com, email:448013559@qq.com
}

Keywords: Fault Tree Analysis; Descending Method; Minimal Cut-set.

\begin{abstract}
In this paper, a fault tree was built for the issue of fuse misfire, which was significant for personal reliability. Herein, the misfire of a certain fuse was regarded as a fault mode. Therefore, a fault tree for the fuse misfire was successfully built. And the descending method was utilized to solve fault tree by calculating the minimal cut-sets of the fault tree. A great many of reference values were successfully obtained with the proposed method. Minimal cut-set can not only conduct the focus controls in the process of the production habitually, but also provide the reference when analyzing the reasons of the fault.
\end{abstract}

\section{Introduction}

Fault tree analysis (FTA) is an effective means of fault analysis which has been accepted widely [1-3]. It can be used to search the reasons of system fault or catastrophe [4-6]. FTA can be used in many phases of product life cycle [7]. In the phase of product designing FTA can help ascertain potential fault and dangerous factors, being convenient for discover the feeble link of reliability and security, while in the phase of product manufacturing and using FTA can help fault diagnosis, so as to improve on the scheme of using and servicing [8].

Cut-set is a collection composed by bottom events of fault tree. If these bottom events all occur, the top event will happen affirmatively. Minimal cut-set is a cut-set whose amount of bottom events can not be decreased [4] [9]. As well, if arbitrary bottom event is taken out from cut-set, the residual collection is not a cut-set any more. A minimal cut-set means an existent fault mode that can make the top event happen [10]. The final purpose of simplifying fault tree is analyzing the reasons which can lead to the fault, through solving minimal cut-set of fault tree.

Misfire is a familiar failure pattern of fuse. In this paper, misfire of a certain fuse was regarded as a fault mode. The fault tree of the fuse misfire was built up, which was solved by descending method. As the minimal cut-set was obtained, the reasons of the fuse misfire were present to our eyes.

\section{Building up the fault tree}

Just as the preamble had described, fuse misfire was the top event of the fault tree, which should be put in the top rectangle frame of the fault tree. According to fuse structure, the immediate reasons were got out using brain storming [11] shown inTab.1.

Tab.1. Immediate causes events of the top event

\begin{tabular}{|c|c|c|c|c|c|}
\hline E1 & Fuse misfire & E4 & Discharge time long & E7 & Upon switch not turn on \\
\hline E2 & $\begin{array}{c}\text { Inter insurance } \\
\text { not discharge }\end{array}$ & E5 & $\begin{array}{c}\text { Detonator } \\
\text { not on fire channel }\end{array}$ & E8 & $\begin{array}{c}\text { Core components } \\
\text { no action }\end{array}$ \\
\hline E3 & $\begin{array}{c}\text { Creepy insurance } \\
\text { not discharge }\end{array}$ & E6 & $\begin{array}{c}\text { Upon switch } \\
\text { not turn on }\end{array}$ & E9 & $\begin{array}{c}\text { Electric detonator } \\
\text { not fire }\end{array}$ \\
\hline
\end{tabular}


And then the top event and immediate causes event were connected by suitable logic gate according the logical relation shown as Fig.1.

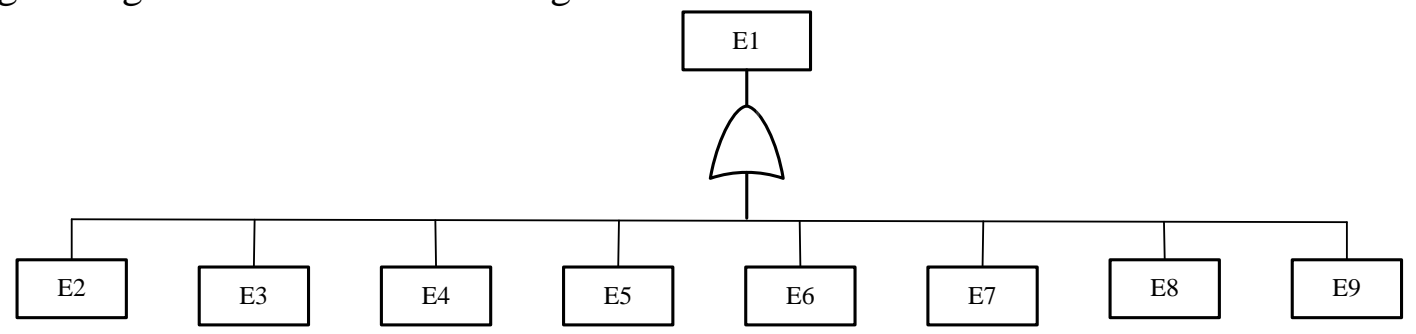

Fig.1. Fault tree of immediate causes event and top event

Using the same way, all the other reasons were got out shown in Tab.2. Among the rest, E10 is basic event like E1 $\sim$ E9, while X1 $\sim \mathrm{X} 27$ are all bottom events. As well, the logical relation was established.

Tab.2. All the other events

\begin{tabular}{|c|c|c|c|c|c|}
\hline E10 & $\begin{array}{l}\text { Close-lock wire } \\
\text { not lock }\end{array}$ & X9 & $\begin{array}{l}\text { Piston outside diameter } \\
\text { surface rough }\end{array}$ & $\mathrm{X} 18$ & $\begin{array}{l}\text { Inertia spring } \\
\text { resistance large }\end{array}$ \\
\hline $\mathrm{X} 1$ & $\begin{array}{l}\text { Inertia cylinder } \\
\text { surface rough }\end{array}$ & $\mathrm{X} 10$ & Discharge hole small & X19 & $\begin{array}{c}\text { Electrical block size } \\
\text { ultra-poor and surface rough }\end{array}$ \\
\hline $\mathrm{X} 2$ & $\begin{array}{l}\text { Inertia cylinder } \\
\text { spring resistance } \\
\text { large }\end{array}$ & $\mathrm{X} 11$ & $\begin{array}{l}\text { Piston spring } \\
\text { resistance small }\end{array}$ & X20 & Safety pin not cut \\
\hline X3 & $\begin{array}{l}\text { Slide seat out hole } \\
\text { surface rough }\end{array}$ & $\mathrm{X} 12$ & Piston deformation & $\mathrm{X} 21$ & $\begin{array}{c}\text { Core component } \\
\text { deformation }\end{array}$ \\
\hline $\mathrm{X} 4$ & $\begin{array}{l}\text { Inertia cylinder } \\
\text { deformation }\end{array}$ & $\mathrm{X} 13$ & $\begin{array}{l}\text { Slide size ultra-poor and } \\
\text { surface rough }\end{array}$ & $\mathrm{X} 22$ & Coil deformation \\
\hline $\mathrm{X} 5$ & $\begin{array}{l}\text { Creepy pin spring } \\
\text { resistance large }\end{array}$ & $\mathrm{X} 14$ & $\begin{array}{c}\text { Slide seat size } \\
\text { ultra-poor and surface } \\
\text { poor }\end{array}$ & $\mathrm{X} 23$ & Electric detonator failure \\
\hline X6 & $\begin{array}{l}\text { Creepy pin outer } \\
\text { surface rough }\end{array}$ & $\mathrm{X} 15$ & $\begin{array}{l}\text { Electrical connection } \\
\text { spring oxidation }\end{array}$ & X24 & $\begin{array}{l}\text { Electronic component } \\
\text { failure }\end{array}$ \\
\hline $\mathrm{X} 7$ & $\begin{array}{l}\text { Creepy pin } \\
\text { deformation }\end{array}$ & $\mathrm{X} 16$ & $\begin{array}{l}\text { Electrical connection } \\
\text { pin oxidation }\end{array}$ & X25 & $\begin{array}{c}\text { Electronic line } \\
\text { disconnect、 void weld }\end{array}$ \\
\hline $\mathrm{X} 8$ & $\begin{array}{l}\text { Slide seat hole inner } \\
\text { surface rough }\end{array}$ & $\mathrm{X} 17$ & $\begin{array}{c}\text { Skeleton size } \\
\text { ultra-poor and surface } \\
\text { rough }\end{array}$ & X26 & Close-lock wire deformation \\
\hline $\mathrm{X} 27$ & \multicolumn{5}{|c|}{ Close-lock wire elasticity not good } \\
\hline
\end{tabular}

Considering the demand of ultimate purpose, the fault tree was built up imperceptibly, until the last line causes events were all bottom events. The image of the fault tree was shown as Fig.2. 


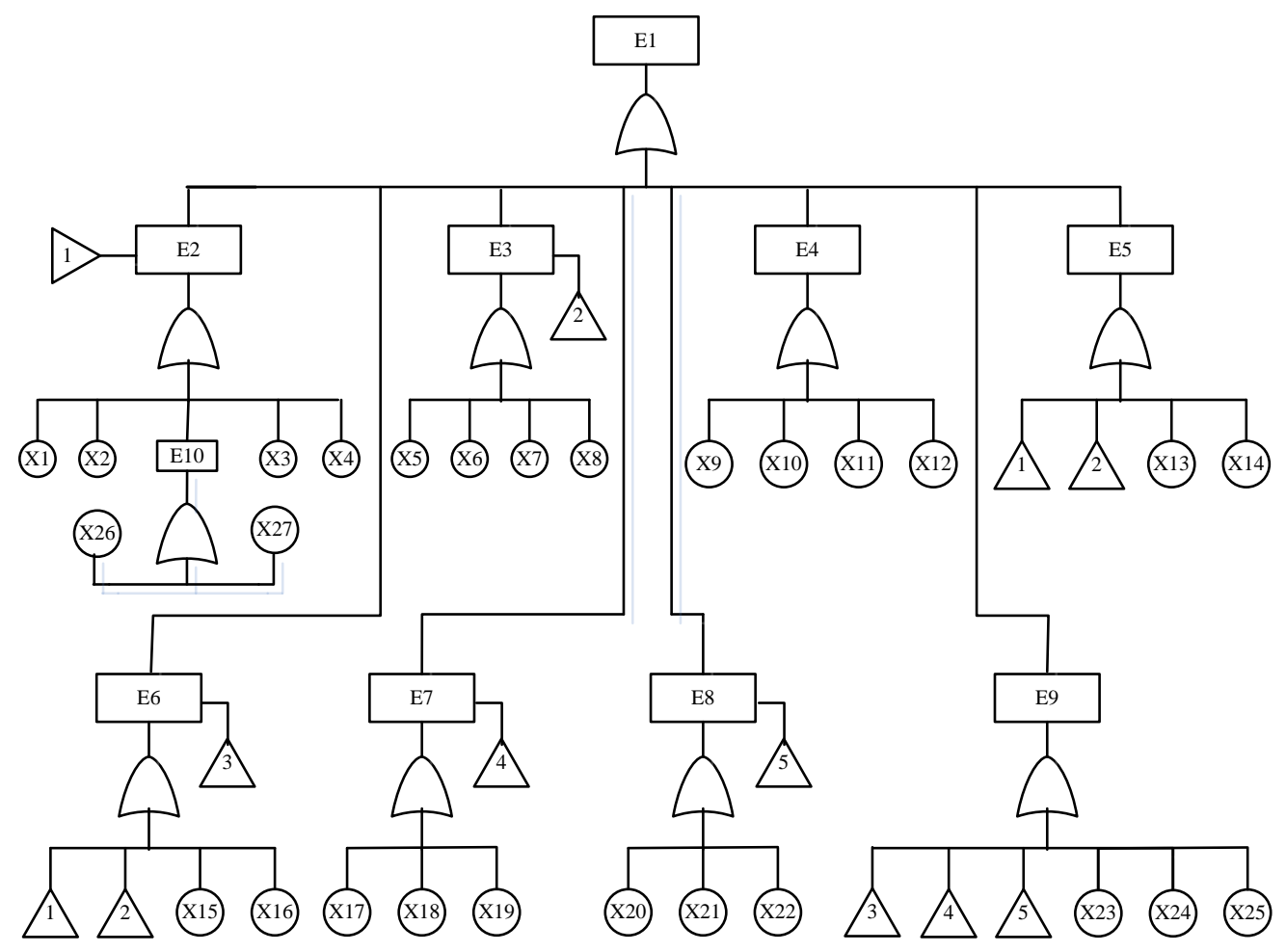

Fig.2. Fault tree of the fuse misfire

\section{Solving the minimal cut-sets}

In common usage, the method of solving minimal cut-set are ascending method and descending method [12]. Ascending method [13] is a kind of set operation that expresses the output event as the Boolean sum of the input event of or-gate, and expresses the output event as the Boolean product of the input event of the and-gate, which takes effect top-down progressively from the bottom event. And then, the expression is solved using Boolean absorption rate and Boolean idempotent rate, immediately the top event is expressed as the sum of products of the bottom event. Among the expression, the whole products are all minimal cut-sets of the fault tree, as well as every item is corresponded to a minimal cut-set of the fault tree.

Descending method [13][14] is a kind of way that finds out cut-sets, which takes effect top-down progressively from the top event, according to the structure of the fault tree. The output event of logic gate must be replaced by the input event sequentially in process of descending. If and-gate appears, the input event of the output event will be put on the same line, while the input event of the output event will be put on the different line if the or-gate appears. When the bottom events are all found out, the non-cut-sets should be scored out through comparing pair. And then the remaining cut-sets are the minimal cut-sets of the fault tree. In order to understand well for the readers who are not good at mathematics, descending method is considered as first choice to solving the minimal cut-sets.

Detailed steps:

Step1 Or-gate is under the top event E1, so the input events of E1 were put on the different array. The cut-sets were shown in the second line of the Tab.3.

Step2 Or-gate is under the event E5, so the input events of E5 were put on the different array. Or-gate is under the event E9, so the input events of E9 were put on the different array. The cut-sets were shown in the third line of the Tab.3.

Step3 The duplicate events were scored out after comparing the input events. The remaining cut-sets were shown in the fourth line of the Tab.3.

Step4 Or-gate is under the event E6, so the input events of E6 were put on the different array. The cut-sets were shown in the fifth line of the Tab.3 after that Step3 was repeated.

Step5 Each Or-gate is under the event E2、E3、E4、E7 and E8, so the input events of E2、E3、 
E4、E7 and E8 were put on the different array. The cut-sets were shown in the sixth line of the Tab.3 after arranging after that Step3 was repeated.

Step6 Or-gate is under the event E10, so the input events of E10 were put on the different array. The cut-sets were shown in the seventh line of the Tab.3 after that Step3 was repeated.

Tab.3. Steps of solving the minimal cut-sets

\begin{tabular}{|c|l|}
\hline Step & \multicolumn{1}{|c|}{ The events of single row } \\
\hline Step 1 & E2, E3, E4, E5, E6, E7, E8, E9, E10 \\
\hline Step 2 & $\begin{array}{l}\text { E2, E3, E4, E2, E3, X13, X14, E6, E7, E8, E3, E4, E5, X23, X24, X25, } \\
\text { E10 }\end{array}$ \\
\hline Step 3 & E2, E3, E4, X13, X14, E6, E7, E8, X23, X24, X25, E10 \\
\hline Step 4 & E2, E3, E4, X13, X14, X15, X16, E7, E8, X23, X24, X25 \\
\hline Step 5 & $\begin{array}{l}\text { X1, X2, X3, X4, E10, X5, X6, X7, X8, X9, X10, X11, X12, X13, X14, } \\
\text { X15, X16, X17, X18, X19, X20, X21, X22, X23, X24, X25 }\end{array}$ \\
\hline Step 6 & $\begin{array}{l}\text { X1, X2, X3, X4, X26, X27, X5, X6, X7, X8, X9, X10, X11, X12, X13, } \\
\text { X14, X15, X16, X17, X18, X19, X20, X21, X22, X23, X24, X25 }\end{array}$ \\
\hline
\end{tabular}

Note: The column is written as line in order to save space.

Up to now, all the minimal cut-sets of the fault tree were found out. Every event which was shown in the seventh line of the Tab.3 can lead fuse misfire. The twenty-seven events will be not only the focus controls in the process of the fuse production, but also the focus when the fault of the fuse misfire happens.

\section{Conclusion}

The example solving minimal cut-sets of fault tree of fuse misfire may not have general meaning, but the descending method which was introduced in this paper has considerable reference values. Minimal cut-set can not only conduct the focus controls in the process of the production habitually, but also provide the reference when analyzing the reasons of the fault.

\section{Acknowledgement}

This work was supported by Mechatronics Co.Ltd of Liaoning Huaxing. Specially, Pengcheng Liu and Bo Wang who are senior engineers gave much help in implementation process of brain storming in order to search all the reasons of the fuse misfire.

\section{References}

[1] Wu C, Meng T R. System Safety Engineering in mines( in Chinese) [M]. Changsha: Central South University of Technology Press, 1992.10-60.

[2] Chao Wu, Desheng Gu. Fault Tree Analysis of Dust Suppression Mechanism in a Spray System with Wetting Agent [J]. J.Cen.South Univ.Technol, 2000, 7(3):118-123.

[3] Yuchang Mo, Hongwei Liu, Xiaozong Yang. Efficient Fault Tree Analysis of Complex Fault Tolerant Multiple-Phased Systems [J]. Tsinghua Science and Technology, 2007, 12(S1):122-127.

[4] Wei Wang, Haiying Cui, Wenhu Huang. A Diagnosis Approach Based on Minimal Cut-sets and Minimal Path Sets of Fault Tree [J]. Journal of Data Acquisition\& Processing, 1999, 14(1):26-29.

[5] Shouquan Wang, Xin Liu. Algorithm of Fault Tree Minimal Cut-set Based on Step Function [J]. Science Technology and Engineering , 2009, 9(12):6741-6743. 
[6] Daqi Zhu, Shenglin Yu. Diagnosis Approach Based on Minimal Cut-set of Fault Trees [J]. Journal of Data Acquisition\& Processing, 2002, 17(3):341-344.

[7] Ya Zhang, Shaofeng Dong. Analysis Procedure of Fault Tree about Fuse [J]. Journal of Taiyuan Institute of Machinery, 1990, 11(2):39-45.

[8] Jinmei Liu, Ningping Li, Hui Gao. Digital Simulation of Fault Tree Analysis about Mechanical Fuse [J]. Journal of Institute of Command and Technology, 1999, 10(5):81-85.

[9] Fanqiang Kong, Xin Zhang, Huixia Zhang. Application of Minimal Cut-sets and Minimal Path-sets of Fault Tree in Rockets Fault Diagnosis [J]. Electronic Design Engineering, 2011, 19(18):8-10.

[10] Zhi Hu, Renkun Yin. Dynamic Generation of Safety Test Case Based on Minimal Cut-sets [J]. Computer Engineering and Design, 2006, 27(16):3018-3020.

[11] The Association of Industrial Quality of Ordnance China. The Thirty-six Methods of Practical Statistical Technique [M]. The Press of Ordnance Industry, 2003:87-92.

[12] Dong Liu, Li Zhang, Yiqun Wang. A Algorithm of Fault Tree Minimal Cut-set Based on Events Sequence [J]. Aeronautical Computing Technique, 2009, 39(2):18-20.

[13] GJB768A-98.The Guide of Fault Tree Analysis [S].

[14] Huizhen Liu, Xiaoguang Fan, Xiaobin Hui, Heyong Zhao. One Advanced Calculation Method for the Least Cut Set and Least Path Set of Fault Tree [J]. Industrial Safety and Environmental Protection, 2006, 32(4):58-59. 